Louisiana State University

LSU Digital Commons

Faculty Publications

Department of Physics \& Astronomy

$1-28-2017$

\title{
The influence of hydrostatic pressure on the magnetic and magnetocaloric properties of DyRu2Si2
}

\author{
Ahmad Us Saleheen \\ Louisiana State University \\ Tapas Samanta \\ Louisiana State University \\ Mojammel Khan \\ Louisiana State University \\ Philip W. Adams \\ Louisiana State University \\ David P. Young \\ Louisiana State University
}

See next page for additional authors

Follow this and additional works at: https://digitalcommons.Isu.edu/physics_astronomy_pubs

\section{Recommended Citation}

Saleheen, A., Samanta, T., Khan, M., Adams, P., Young, D., Dubenko, I., Ali, N., \& Stadler, S. (2017). The influence of hydrostatic pressure on the magnetic and magnetocaloric properties of DyRu2Si2. Journal of Applied Physics, 121 (4) https://doi.org/10.1063/1.4974466

This Article is brought to you for free and open access by the Department of Physics \& Astronomy at LSU Digital Commons. It has been accepted for inclusion in Faculty Publications by an authorized administrator of LSU Digital Commons. For more information, please contact ir@lsu.edu. 


\section{Authors}

Ahmad Us Saleheen, Tapas Samanta, Mojammel Khan, Philip W. Adams, David P. Young, Igor Dubenko, Naushad Ali, and Shane Stadler 


\section{The influence of hydrostatic pressure on the magnetic and magnetocaloric properties of $\mathrm{DyRu}_{2} \mathrm{Si}_{2}$}

Ahmad Us Saleheen, Tapas Samanta, Mojammel Khan, Philip W. Adams, David P. Young, Igor Dubenko, Naushad Ali, and Shane Stadler

Citation: Journal of Applied Physics 121, 045101 (2017); doi: 10.1063/1.4974466

View online: https://doi.org/10.1063/1.4974466

View Table of Contents: http://aip.scitation.org/toc/jap/121/4

Published by the American Institute of Physics

\section{Articles you may be interested in}

Universal field dependence of conventional and inverse magnetocaloric effects in $\mathrm{DyC}_{2} \mathrm{Si}_{2}$

Journal of Applied Physics 121, 043901 (2017); 10.1063/1.4974302

Magnetization reversal behavior and magnetocaloric effect in $\mathrm{SmCr}_{0.85} \mathrm{Mn}_{0.15} \mathrm{O}_{3}$ chromites

Journal of Applied Physics 121, 043907 (2017); 10.1063/1.4974737

Effects of the partial substitution of $\mathrm{Ni}$ by $\mathrm{Cr}$ on the transport, magnetic, and magnetocaloric properties of $\mathrm{Ni}_{50} \mathrm{Mn}_{37} \ln _{13}$

AIP Advances 7, 056433 (2017); 10.1063/1.4978909

Giant field-induced adiabatic temperature changes in In-based off-stoichiometric Heusler alloys

Journal of Applied Physics 121, 133901 (2017); 10.1063/1.4979475

Magnetocaloric effect in the metamagnet ErRhSi compound

Journal of Applied Physics 120, 233902 (2016); 10.1063/1.4971959

Observation of large magnetocaloric effect in equiatomic binary compound ErZn

AIP Advances 7, 056401 (2017); 10.1063/1.4972796

\section{AIP |roumal if}

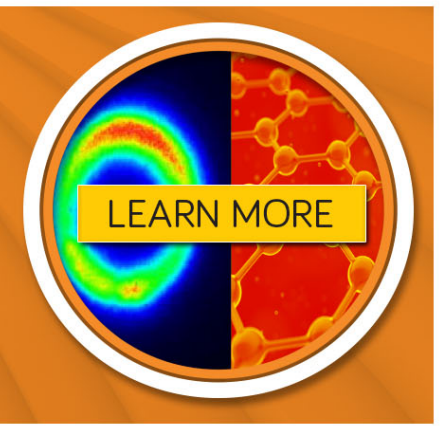




\title{
The influence of hydrostatic pressure on the magnetic and magnetocaloric properties of $\mathrm{DyRu}_{2} \mathrm{Si}_{2}$
}

\author{
Ahmad Us Saleheen, ${ }^{1, a)}$ Tapas Samanta, ${ }^{1}$ Mojammel Khan, ${ }^{1}$ Philip W. Adams, ${ }^{1}$ \\ David P. Young, ${ }^{1}$ Igor Dubenko, ${ }^{2}$ Naushad Ali, ${ }^{2}$ and Shane Stadler ${ }^{1}$ \\ ${ }^{1}$ Department of Physics and Astronomy, Louisiana State University, Baton Rouge, Louisiana 70803, USA \\ ${ }^{2}$ Department of Physics, Southern Illinois University, Carbondale, Illinois 62901, USA
}

(Received 17 October 2016; accepted 8 January 2017; published online 24 January 2017)

\begin{abstract}
We report the magnetic and magnetocaloric properties of the tetragonal rare-earth compound DyRu $\mathrm{Si}_{2}$ under applied hydrostatic pressure. The isothermal entropy change $(\Delta \mathrm{S})$ and the adiabatic temperature change $\left(\Delta \mathrm{T}_{\mathrm{ad}}\right)$ were calculated from magnetization data collected at different applied pressures and from heat capacity measurements conducted at atmospheric pressure, respectively. The application of hydrostatic pressure significantly modified the multi-step magnetization curve and the saturation magnetization. A suppression of the magnetization was observed for $\mathrm{P}=0.588 \mathrm{GPa}$ and $\mathrm{P}=0.654 \mathrm{GPa}$ whereas, at about $\mathrm{P} \approx 1 \mathrm{GPa}$, the saturation magnetization increased and the magnetization isotherms again resembled the curves measured at atmospheric pressure. A small thermal hysteresis was observed between the heating and cooling $\mathrm{M}(\mathrm{T})$ curves at $\mathrm{T}_{\mathrm{t}}=3.4 \mathrm{~K}$, with an applied magnetic field of $\mathrm{H}=0.1 \mathrm{~T}$. This thermal hysteresis indicates a firstorder like transition which was also supported by the Arrott plot analysis. The volume magnetostriction was estimated from the pressure-dependent magnetization measurements using a Maxwell relation. Published by AIP Publishing. [http://dx.doi.org/10.1063/1.4974466]
\end{abstract}

\section{INTRODUCTION}

Magnetic cooling technology based on the magnetocaloric effect (MCE) has evolved as a viable technological alternative to conventional cooling technology based on the vapor compression cycle. ${ }^{1,2}$ The MCE is the isothermal entropy change or adiabatic temperature change of a magnetic material when subjected to an external magnetic field. Extensive research has revealed classes of materials, such as $\mathrm{Gd}_{5} \mathrm{Si}_{2} \mathrm{Ge}_{2},{ }^{3}$ MnAs-based compounds, ${ }^{4,5} \mathrm{La}\left(\mathrm{Fe}{ }_{1-x} \mathrm{Si}_{x}\right)_{13},{ }^{6}$ $\mathrm{Mn}(\mathrm{Co}, \mathrm{Ni}) \mathrm{Ge}$-based compounds, and ${ }^{7-10} \mathrm{Ni}_{2} \mathrm{MnGa}$ and $\mathrm{Ni}_{2} \mathrm{MnIn}$-based Heusler alloys, ${ }^{11,12}$ all of which show large MCEs near room temperature. A large MCE at low temperature is also useful for specific technological purposes, such as space science and, most prominently, in gas liquefaction. $^{13-15}$ Antiferromagnetic (AFM) systems can be good candidates in the cryogenic temperature range since they may show large MCE values due to magnetic-field-induced metamagnetic transitions from antiferromagnetic (AFM) to ferromagnetic (FM) states. ${ }^{13}$ In this study, we report our findings on the magnetocaloric and magnetic properties of DyRu $\mathrm{Si}_{2}$. This compound belongs to a class of materials with the general formula $\mathrm{RT}_{2} \mathrm{X}_{2}$, where $\mathrm{R}$ is a rare earth element, $\mathrm{T}$ is a transition metal, and $\mathrm{X}$ is silicon or germanium. These materials show a wide variety of properties such as heavy fermionic behavior, superconductivity, and complex and multiple magnetic transitions. ${ }^{16}$

DyRu $\mathrm{Si}_{2}$ crystallizes in the body centered tetragonal $\mathrm{ThCr}_{2} \mathrm{Si}_{2}$-type structure with space group $14 / \mathrm{mmm}$, where only the Dy atoms possess a magnetic moment. ${ }^{17-20}$ In the temperature range $2-400 \mathrm{~K}, \mathrm{DyRu}_{2} \mathrm{Si}_{2}$ shows two magnetic

${ }^{\text {a)} E l e c t r o n i c ~ m a i l: ~ a u s s a l 1 @ 1 s u . e d u ~}$ transitions (M vs. T), and multi-step metamagnetic transitions (M vs. $\mathrm{H}$ ) at low temperature. We observed a maximum total isothermal entropy change $\left(\Delta \mathrm{S}_{\mathrm{T}}\right)$ of $-6.6 \mathrm{~J} / \mathrm{kg} \mathrm{K}$ at $\mathrm{T}=29.2 \mathrm{~K}$ for a $7 \mathrm{~T}$ magnetic field change, calculated from magnetization isotherms. From field-dependent heat capacity data, we calculated an adiabatic temperature change $\left(\Delta \mathrm{T}_{\mathrm{ad}}\right)$ of $8.2 \mathrm{~K}$ at $\mathrm{T}=5.1 \mathrm{~K}$ for a $5 \mathrm{~T}$ magnetic field change. For comparison, other materials in this class, $\mathrm{GdCr}_{2} \mathrm{Si}_{2},{ }^{21} \mathrm{HoRu}_{2} \mathrm{Si}_{2},{ }^{14}$ and $\mathrm{ErRu}_{2} \mathrm{Si}_{2},{ }^{13}$ were reported to show the entropy changes $(\Delta \mathrm{S})$ of $14.1 \mathrm{~J} / \mathrm{kg} \mathrm{K}, 9.1 \mathrm{~J} / \mathrm{kg} \mathrm{K}$, and $19.3 \mathrm{~J} / \mathrm{kg} \mathrm{K}$ at $\mathrm{T}=8 \mathrm{~K}$, $19 \mathrm{~K}$, and $5.5 \mathrm{~K}$, respectively, for a field change of $5 \mathrm{~T}$. In the case of $\mathrm{ErRu}_{2} \mathrm{Si}_{2}$, an adiabatic temperature change $\left(\Delta \mathrm{T}_{\mathrm{ad}}\right)$ of $12.9 \mathrm{~K}$ was found at $\mathrm{T}=5.5 \mathrm{~K}$ for a $5 \mathrm{~T}$ magnetic field change. $\mathrm{DyRu}_{2} \mathrm{Si}_{2}$ showed magnetostrictive behavior, and the volume magnetostriction $(\Delta \mathrm{V} / \mathrm{V})$ was estimated from the pressuredependent magnetization measurements. Hydrostatic pressure significantly altered the saturation magnetization and magnetic interactions, as well as the magnetocaloric properties of this compound.

\section{EXPERIMENTAL METHODS}

Polycrystalline $\mathrm{DyRu}_{2} \mathrm{Si}_{2}$ buttons (approximately $2 \mathrm{~g}$ ) were fabricated from high-purity elements (better than 99.9\%) $\mathrm{Dy}, \mathrm{Ru}$, and $\mathrm{Si}$ by conventional arc-melting in an argon atmosphere. The weight loss after melting was found to be less than $0.3 \%$. The samples were placed inside an evacuated quartz tube and annealed at $750{ }^{\circ} \mathrm{C}$ in a tube furnace for 5 days and slowly cooled to room temperature. X-ray diffraction (XRD) measurements were done with a room-temperature $\mathrm{X}$-ray diffractometer using $\mathrm{CuK} \alpha$ radiation and $\theta-\theta$ geometry. Magnetization measurements within a temperature interval of $2-400 \mathrm{~K}$ and up to $7 \mathrm{~T}$ magnetic fields were done with a 
superconducting quantum interference device magnetometer [SQUID, Quantum Design magnetic property measurement system (MPMS)]. Irregularly shaped samples of about $3 \mathrm{mg}$ were used in these measurements. Magnetic measurements under hydrostatic pressure were performed using a commercial $\mathrm{BeCu}$ cylindrical pressure cell manufactured by Quantum Design. Daphne 7373 oil was used as the pressure transmitting medium. The magnitude of the applied pressure was calibrated by measuring the shift of the superconducting transition temperature of $\mathrm{Pb}$, which was placed in the cell with the sample as a reference manometer. Heat capacity measurements were done on a Quantum Design Physical Properties Measurement System (PPMS). For this purpose, a $4.4 \times 1 \times$ $0.6 \mathrm{~mm}$ sample of around $18 \mathrm{mg}$ was cut using a spark cutter.

\section{RESULTS AND DISCUSSION}

From the room temperature XRD pattern for $\mathrm{DyRu}_{2} \mathrm{Si}_{2}$ (Fig. 1), the $\mathrm{ThCr}_{2} \mathrm{Si}_{2}$-type tetragonal structure was verified. The lattice parameters were calculated as $a=4.147(8) \AA$ and $c=9.522(8) \AA$, consistent with the previously reported values. ${ }^{22}$ The magnetization as a function of temperature $(\mathrm{M}$ vs. $\mathrm{T}$ ) with $\mathrm{H}=0.1 \mathrm{~T}$ at atmospheric pressure is shown in Fig. 2. Two magnetic transitions, one at $\mathrm{T}_{\mathrm{N}}=29.2 \mathrm{~K}$ and another at $\mathrm{T}_{\mathrm{t}}=3.4 \mathrm{~K}$, are clearly visible. A small but distinct hysteresis of about $0.3 \mathrm{~K}$ was observed between the zero-field-cooled (ZFC) warming and field-cooled-cooling (FCC) curves in the temperature range of $8 \mathrm{~K}$ to around $\mathrm{T}_{\mathrm{t}}=3.4 \mathrm{~K}$. Previous studies reported another transition at $\mathrm{T}_{\mathrm{t}}^{\prime}=1.5 \mathrm{~K},{ }^{17,18}$ (and references therein) but this was beyond the temperature range of our instrument. $\mathrm{DyRu}_{2} \mathrm{Si}_{2}$ has three temperature-dependent phases, namely: a low temperature phase (LTP) below $\mathrm{T}_{\mathrm{t}}^{\prime}$, an intermediate temperature phase (ITP) at $\mathrm{T}_{\mathrm{t}}^{\prime}<\mathrm{T}<\mathrm{T}_{\mathrm{t}}$, and a high temperature phase (HTP) at $\mathrm{T}_{\mathrm{t}}<\mathrm{T}<\mathrm{T}_{\mathrm{N}} .{ }^{17,18}$

According to the model proposed by Kawano et al., ${ }^{17,18}$ the ITP has a two dimensional spin configuration with a magnetic unit cell of $9 a \times 9 a \times c$, where $a$ and $c$ represent the lattice constants of the chemical unit cell. In the same study, the spin configuration for the HTP had been shown to exhibit a one dimensional magnetic structure. In light of this model, at $T_{t}$ the system transforms from a one dimensional

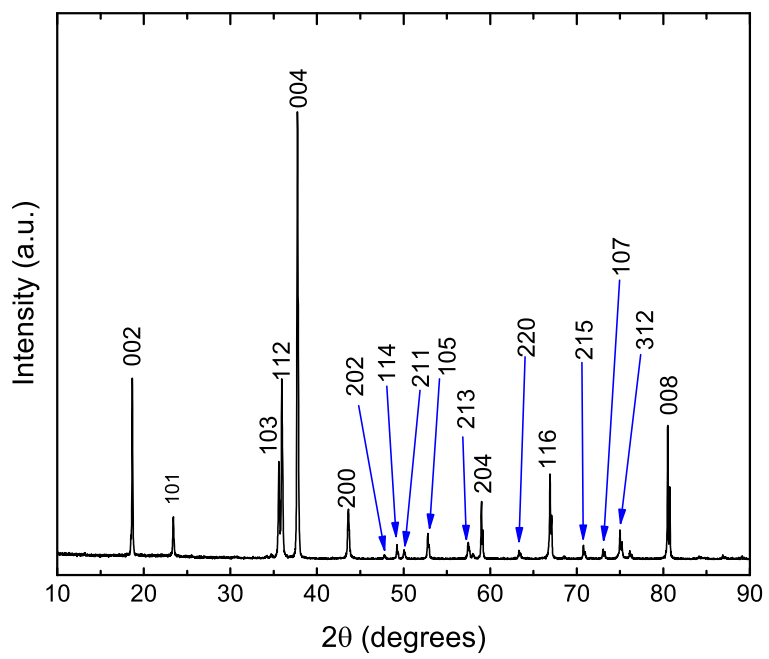

FIG. 1. Room temperature powder XRD pattern for $\mathrm{DyRu}_{2} \mathrm{Si}_{2}$.

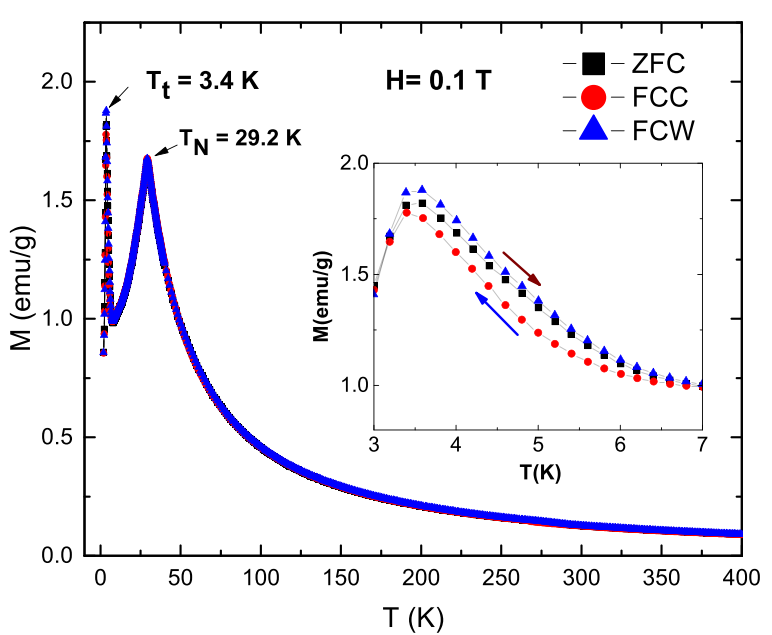

FIG. 2. Magnetization (M) vs. temperature (T) for $\mathrm{DyRu}_{2} \mathrm{Si}_{2}$ at $\mathrm{H}=0.1 \mathrm{~T}$ applied field at atmospheric pressure. (Inset) Zoomed-in view of the same data to show the thermal hysteresis.

magnetic structure to a two dimensional structure upon cooling, giving rise to a high magnetization phase that is evident from the peak in the magnetization around $T_{t}$. The origin of the thermal hysteresis in the M vs. T data may be the orderorder transition between the two-dimensional and onedimensional magnetic configurations.

Fig. 3 shows the Arrott plot analysis of the magnetization isotherms at atmospheric pressure for some selected temperatures around $T_{t}$ and $T_{N}$. It is known (Banerjee criterion $)^{23}$ that a negative slope in the Arrott plot is an indication of a first-order magnetic transition, whereas a positive slope indicates a second-order transition. The curves around $T_{t}$ formed "S" like shapes with negative slopes at lower field values and positive slopes at higher fields. This occurrence of a negative curvature in Arrott plots is usually associated with a first-order magnetic transition. ${ }^{21,24-28}$ The small temperature hysteresis in the $\mathrm{M}$ vs. $\mathrm{T}$ data also points towards the first-order nature of the transition at $T_{t}$. Curves showing negative slopes continue up to the Néel temperature $\left(T_{N}\right)$ and, starting from $30 \mathrm{~K}$, they start to have positive slopes even at low fields. At higher temperatures, no negative

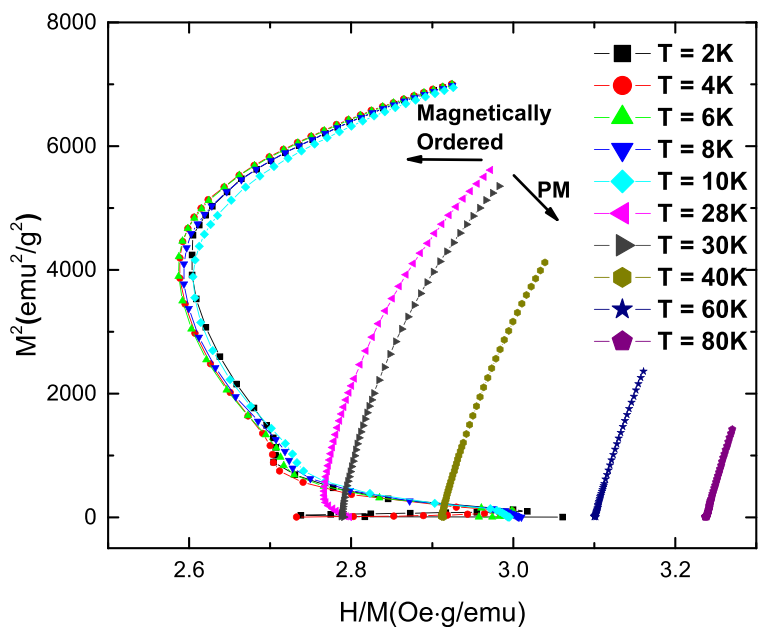

FIG. 3. Arrott plots of the magnetization data for $\mathrm{DyRu}_{2} \mathrm{Si}_{2}\left(\mathrm{M}^{2}\right.$ vs. H/M) at selected temperatures and atmospheric pressure. 
slopes were observed, implying a second-order transition to a paramagnetic (PM) state. We also attempted to construct a universal curve for the entropy change at an atmospheric pressure (not shown), in light of the works by Franco and Conde. ${ }^{29}$ For materials showing second-order magnetic transitions, the $\Delta \mathrm{S}$ vs. $\mathrm{T}$ curves measured at different fields should collapse into a single curve upon rescaling of the temperature axis, whereas failure to collapse is considered to be an indication of a first-order transition. ${ }^{29,30}$ In our case, the curves collapsed into a single universal curve around $\mathrm{T}_{\mathrm{N}}$. However, below $\mathrm{T}_{\mathrm{N}}$, and around $\mathrm{T}_{\mathrm{t}}$, the curves failed to collapse. This could be construed as an indication of a firstorder transition, however, this view was challenged by Smith et al., ${ }^{31}$ arguing that there was no one-to-one connection between the behavior of the scaling procedure and the order of the phase transition. Based on these findings, and especially the observed thermal hysteresis, it is plausible that the magnetic phase transition at $\mathrm{T}_{\mathrm{t}}$ is first-order like.

Fig. 4 shows the magnetization isotherms at $2 \mathrm{~K}$ at various pressures. In increasing field, three distinct transitions were observed with critical fields of $\mathrm{H}_{1}=0.2 \mathrm{~T}, \mathrm{H}_{2}=1.2 \mathrm{~T}$, and $\mathrm{H}_{3}=2.2 \mathrm{~T}$, consistent with previous reports. ${ }^{19}$ For pressures of $\mathrm{P}=0.588$ and $0.654 \mathrm{GPa}$, the transitions at $\mathrm{H}>0.2 \mathrm{~T}$ were suppressed (barely discernible in the data). At a pressure of $0.934 \mathrm{GPa}$, these phases return and, at $1.24 \mathrm{GPa}$, they have nearly the same critical fields as they had had at atmospheric pressure. Moreover, at atmospheric pressure, although the $\mathrm{M}$ vs. $\mathrm{H}$ curve does not fully saturate even at $7 \mathrm{~T}$, a saturation tendency could be seen around $\mathrm{H}=3 \mathrm{~T}$. For pressures of $\mathrm{P}=0.588$ and $0.654 \mathrm{GPa}$, this saturation tendency was not observed, and the curves follow a nearly linear dependence on increasing field, pointing towards a weaker magnetic ordering. Also, the magnetization values at $\mathrm{H}=7 \mathrm{~T}$ for $\mathrm{P}=0.588$ and $0.654 \mathrm{GPa}$ are considerably smaller than those at atmospheric pressure. This saturation tendency and non-linearity return at $0.934 \mathrm{GPa}$, and continue up to $1.24 \mathrm{GPa}$, but the magnetization starts to saturate at a higher field value than that observed at atmospheric pressure. Moreover, the magnetization at $\mathrm{H}=7 \mathrm{~T}$ is larger for $\mathrm{P}=1.24 \mathrm{GPa}$ than at atmospheric pressure.

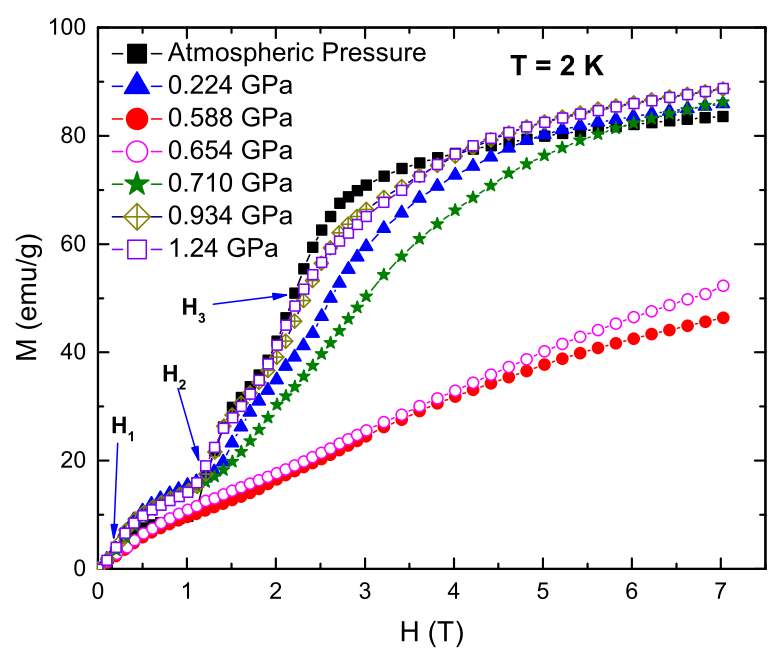

FIG. 4. Magnetization (M) vs. magnetic field $(\mathrm{H})$ for $\mathrm{DyRu}_{2} \mathrm{Si}_{2}$ at $\mathrm{T}=2 \mathrm{~K}$ for various applied hydrostatic pressures.
Heavy rare-earth elements, such as pure Dy and materials consisting of rare-earth elements often exhibit magnetostriction, ${ }^{32-34}$ which lead us to explore the magnetostrictive properties of this compound. Using the Maxwell relation

$$
\left(\frac{\partial M}{\partial P}\right)_{H, T}=-\left(\frac{\partial V}{\partial H}\right)_{P, T},
$$

we calculated the volume magnetostriction, $\Delta \mathrm{V} / \mathrm{V}$, where $\mathrm{V}$ is the volume of the unit cell calculated from the lattice parameters obtained from the XRD measurements. In Eq. (1), $\mathrm{M}$ is the magnetization, $\mathrm{P}$ is the applied pressure, $\mathrm{V}$ is the volume, and $\mathrm{H}$ is the applied magnetic field. This method was also applied by Nikitin et al. ${ }^{33,34}$ to estimate the volume magnetostriction in single crystals of Dy and $\mathrm{Y}_{2} \mathrm{Fe}_{17}$. Fig. 5 shows the temperature dependence of the volume magnetostriction at various pressures. At low fields, a peak in the volume magnetostriction was observed around $\mathrm{T}_{\mathrm{N}}$. This is consistent with the observation that the onset of magnetic ordering gives rise to magnetostriction in heavy rare earth metals as reported by Nikitin et al. ${ }^{35}$ As the magnetic field increases, the magnitude of the volume magnetostriction increases, and the peak in the $\Delta \mathrm{V} / \mathrm{V}$ vs. $\mathrm{T}$ curves shifts towards lower temperatures. The highest value of the volume magnetostriction was found to be $0.35 \%$ at $\mathrm{H}=7 \mathrm{~T}$ and an applied pressure of $\mathrm{P}=0.588 \mathrm{GPa} . \mathrm{A}$ volume magnetostriction of $0.7 \times 10^{-3}$ at a field of $1.2 \mathrm{~T}$ was reported for a pure Dy single crystal, ${ }^{33}$ whereas we calculated a value of $0.1 \times 10^{-3}$ for the same magnetic field. For pressures of $\mathrm{P}>0.588 \mathrm{GPa}$, the volume magnetostriction decreased systematically, as shown in Fig. 6(a).

The presence of magnetostriction in this compound can be attributed to the variation of magnetic properties due to applied hydrostatic pressure. This kind of pressure dependent behavior had been observed in invar alloys, heavy rare-earth elements such as $\mathrm{Tb}$, Gd, Dy, etc., Tb-Gd alloys, and others. ${ }^{36,37}$ According to Eq. (1), sharp changes in magnetization with pressure result in volume changes. We observed large changes in the magnetic properties of $\mathrm{DyRu}_{2} \mathrm{Si}_{2}$ at pressures of $\mathrm{P}=0.588$ and $0.654 \mathrm{GPa}$ which were translated into volume changes as expected from the Maxwell relation (Eq. (1)). As pointed out by Doerr et al., crystal field and exchange striction are the two most important mechanisms for magnetostriction in rare-earth systems. ${ }^{32}$ Tomala et al. ${ }^{38}$ studied the crystal field properties of $\mathrm{DyRu}_{2} \mathrm{Si}_{2}$ by Mössbauer spectroscopy and calculated the crystal electric field (CEF) parameters, $B_{2}^{0}$ with an anomalously large value of $-4.94 \mathrm{~K}$ and $B_{4}^{0}$ with a value of $0.0050 \mathrm{~K}$. With the application of pressure, both the crystal electric field environment and the exchange interaction can change. However, identifying the mechanism that plays the dominant role in the magnetostriction requires further investigation involving single crystals.

The total entropy change was calculated from the magnetization isotherms using the integrated Maxwell relation

$$
\Delta S_{T}(T)=\int_{0}^{H^{\prime}}\left(\frac{\partial M}{\partial T}\right)_{H} d H .
$$

Fig. 7 shows the temperature dependence of $\Delta S_{T}$ for fields up to $7 \mathrm{~T}$ at various pressures. At atmospheric pressure, 


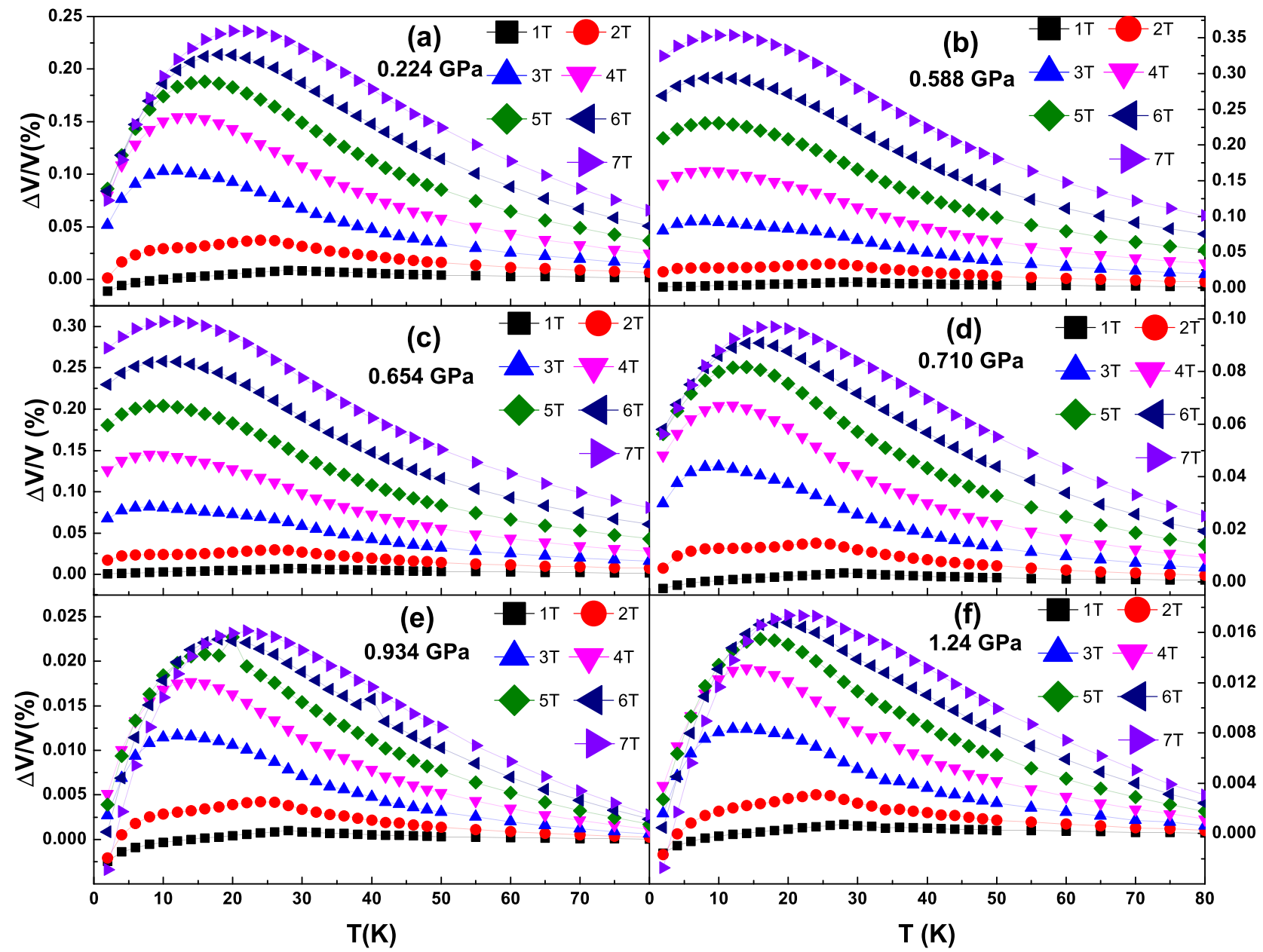

FIG. 5. (a)-(f) Temperature (T) dependence of the volume magnetostriction $(\Delta \mathrm{V} / \mathrm{V})$ of $\mathrm{DyRu}_{2} \mathrm{Si}_{2}$ at magnetic fields up to $7 \mathrm{~T}$ for various pressures $(\mathrm{P})$.

peaks were observed around $\mathrm{T}_{\mathrm{N}}$, and the highest value of $\Delta \mathrm{S}_{\mathrm{T}}$ was $-6.6 \mathrm{~J} / \mathrm{kg} \mathrm{K}$ at $\mathrm{T}=29 \mathrm{~K}$ for $\Delta \mathrm{H}=7 \mathrm{~T}$. An inverse $\operatorname{MCE}\left(\Delta \mathrm{S}_{\mathrm{T}}=2.2 \mathrm{~J} / \mathrm{kg} \mathrm{K}\right)$ was also observed at $\mathrm{T}=3 \mathrm{~K}$ for $\Delta \mathrm{H}=7 \mathrm{~T}$, at this pressure. As the temperature increases beyond $3 \mathrm{~K}$, the inverse MCE vanishes and a normal MCE emerges. For the $1 \mathrm{~T}$ curve, the inverse MCE starts at $5 \mathrm{~K}$ and continues up to $27 \mathrm{~K}$. This inverse MCE could be

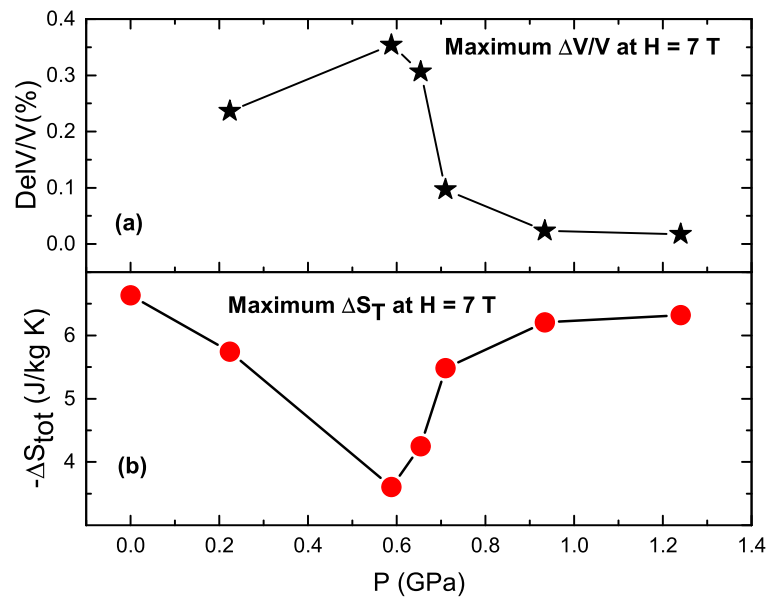

FIG. 6. (a) The maximum values of $\Delta \mathrm{V} / \mathrm{V}$ at $\mathrm{H}=7 \mathrm{~T}$ for $\mathrm{DyRu}_{2} \mathrm{Si}_{2}$ at various applied pressures. (b) The maximum values of $\Delta \mathrm{S}_{\mathrm{T}}$ at $\mathrm{H}=7 \mathrm{~T}$ for various applied pressures. associated with the low-temperature AFM phase. Subtle but clear signs of the transition at $\mathrm{T}_{t}$ were also evident, especially at lower fields. The value of $\Delta \mathrm{S}_{\mathrm{T}}$ decreased at an applied pressure of $0.588 \mathrm{GPa}$ and, in this case, two distinct peaks were observed, one at $5 \mathrm{~K}$ (around $\mathrm{T}_{\mathrm{t}}$ ) and the other at $31 \mathrm{~K}$ (around $\mathrm{T}_{\mathrm{N}}$ ) with $\Delta \mathrm{S}_{\mathrm{T}}$ values of -3.6 and $-2.4 \mathrm{~J} / \mathrm{kg} \mathrm{K}$, respectively. It was noted that, at this pressure, the largest value of $\Delta \mathrm{S}_{\mathrm{T}}$ was found near $\mathrm{T}_{\mathrm{t}}$ rather than at $\mathrm{T}_{\mathrm{N}}$. This scenario prevails at $\mathrm{P}=0.654 \mathrm{GPa}$ but, at $\mathrm{P}=0.710 \mathrm{GPa}$, the largest value of $\Delta \mathrm{S}_{\mathrm{T}}$ was again observed at $\mathrm{T}_{\mathrm{N}}$. This trend continues up to the highest applied pressure of $1.24 \mathrm{GPa}$. After the initial decrease of the overall values of $\Delta S_{T}$ for applied pressures of $0.588 \mathrm{GPa}$ and $0.654 \mathrm{GPa}$, the values start to increase at pressures exceeding $0.710 \mathrm{GPa}$. At $\mathrm{P}=1.24 \mathrm{GPa}$, the peak value of $-6.3 \mathrm{~J} / \mathrm{kg} \mathrm{K}$ at $\mathrm{H}=7 \mathrm{~T}$ is very close to the atmospheric pressure value of $-6.6 \mathrm{~J} / \mathrm{kg} \mathrm{K}$ (Fig. 6(b)). Moreover, the overall shape and features of the curves at $\mathrm{P}=1.24 \mathrm{GPa}$ are similar to those at atmospheric pressure. This tendency was also observed in the $\mathrm{M}$ vs. $\mathrm{H}$ curves at different pressures (Fig. 4).

The origin of this pressure-dependent behavior may lie with the change of the $\mathrm{a} / \mathrm{c}$ ratio with pressure. As pointed out by Szytula et al., ${ }^{16}$ in $\mathrm{RT}_{2} \mathrm{X}_{2}$ systems, the magnetic interaction is governed by the Ruderman-Kittel-Kasuya-Yosida (RKKY) model and the a/c ratio plays a crucial role in defining the nature and strength of the interaction. In $\mathrm{RT}_{2} \mathrm{X}_{2}$ 


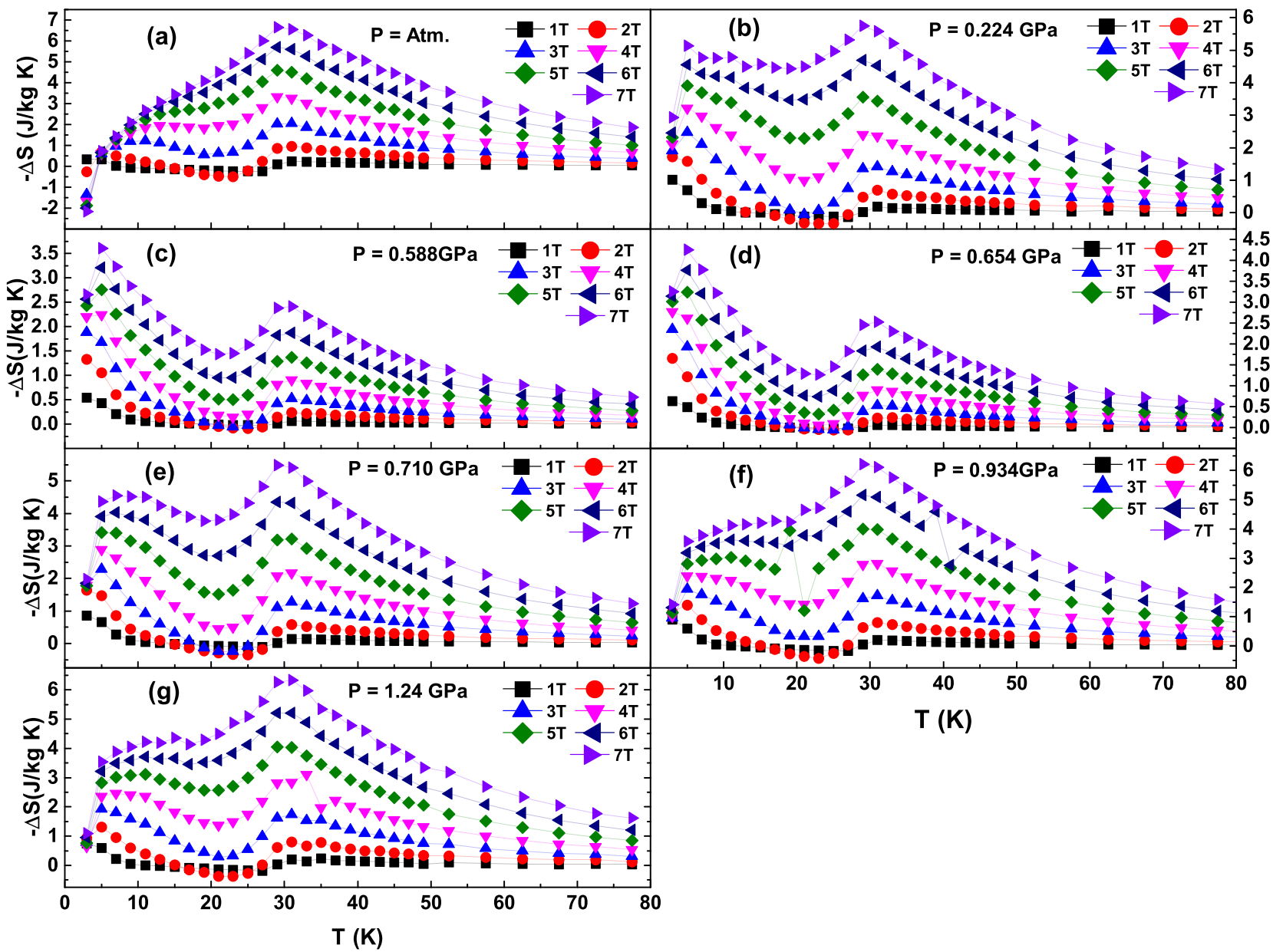

FIG. 7. (a)-(g) Temperature (T) dependence of the total entropy change ( $\Delta \mathrm{S})$ of $\mathrm{DyRu}_{2} \mathrm{Si}_{2}$ for various changes in applied magnetic field (H) and pressure (P).

systems containing heavy rare earths $(\mathrm{R}=\mathrm{Tb}-\mathrm{Tm})$, a simple collinear AFM structure is observed when $a / c<0.415$ and oscillatory magnetic structures emerge when $a / c>0.415$. At atmospheric pressure, DyRu ${ }_{2} \mathrm{Si}_{2}$ has an a/c ratio of 0.435 , well above the critical value of 0.415 . At pressures of 0.588 and $0.654 \mathrm{GPa}$, the $\mathrm{M}$ vs. $\mathrm{H}$ (Fig. 4) data at $\mathrm{T}=2 \mathrm{~K}$ point toward a simpler AFM structure than that which occurs at atmospheric pressure. But for $\mathrm{P}>0.710 \mathrm{GPa}$, the curves again resemble those measured at atmospheric pressure. From this fact, and from Fig. 4, it is plausible that, at pressures of 0.588 and $0.654 \mathrm{GPa}$, the system favors a simpler AFM-like interaction, while at atmospheric pressure and at pressures greater than $0.654 \mathrm{GPa}$, the system tends toward more complicated interactions. Also, the exchange integral depends on the interatomic distances. ${ }^{36}$ The change in volume, and hence the interatomic distances, due to applied pressure can affect the exchange integral, resulting in a variation of magnetic interactions. The observed variation in magnetic properties with pressure can possibly be attributed to the oscillatory nature of the RKKY interaction.

As there is a volume anomaly due to magnetostriction, the total field-induced entropy change is a sum of the magnetic and structural entropy changes, ${ }^{39,40}$ i.e.,

$$
\Delta S_{T}=\Delta S_{m a g}+\Delta S_{s t r}
$$

Gschneidner et al. ${ }^{39}$ compiled a collection of $\Delta \mathrm{S}_{\text {str }}$ (i.e., structural contribution to the total entropy change) for different materials undergoing magnetostructural transitions, as well as volume anomalies, and found a linear relationship between $\Delta \mathrm{S}_{\text {str }}$ and $\Delta \mathrm{V} / \mathrm{V}$. In light of this, we can use the relation$\operatorname{ship}^{41,42} \delta[\Delta V / V(\%)] / \delta\left[\Delta S_{\text {str }}\right]=0.08(\mathrm{~J} / \mathrm{kg} \mathrm{K})^{-1}$ to estimate the structural contribution to the total entropy change. According to this relation, the observed volume magnetostriction of $0.35 \%$ at $\mathrm{H}=7 \mathrm{~T}$ and $\mathrm{P}=0.588 \mathrm{GPa}$ corresponds to a structural entropy change of $\Delta S_{\text {str }}=4.4 \mathrm{~J} / \mathrm{kg} \mathrm{K}$. In Fig. 6, it can be seen that, as the pressure increases, the volume magnetostriction $\Delta \mathrm{V} / \mathrm{V}$, and therefore $\Delta \mathrm{S}_{\text {str }}$, decrease, whereas the value of the total entropy change $\left(\Delta \mathrm{S}_{\mathrm{T}}\right)$ increases. This may indicate that the structural entropy change $\left(\Delta \mathrm{S}_{\mathrm{str}}\right)$ opposes the magnetic entropy change $\left(\Delta \mathrm{S}_{\mathrm{mag}}\right)$, thereby reducing $\Delta \mathrm{S}_{\mathrm{T}}$.

From the zero-field heat capacity measurements at atmospheric pressure (Fig. 8), a well defined anomaly was observed starting at $\mathrm{T}=28.3 \mathrm{~K}$ and ending at $\mathrm{T}=29.3 \mathrm{~K}$ with a drop of about $11.8 \mathrm{~J} / \mathrm{kg} \mathrm{K}$ during heating, which is a characteristic of magnetic ordering. No clear signature of an anomaly was observed in the $\mathrm{C}(\mathrm{T})$ data around $\mathrm{T}_{\mathrm{t}}=3.4 \mathrm{~K}$, probably due to low resolution in that temperature range. However, a sharp spike in the $\mathrm{C} / \mathrm{T}$ vs. $\mathrm{T}$ plot as shown in Fig. 8(b) was observed around $\mathrm{T}=2 \mathrm{~K}$ and $29 \mathrm{~K}$.

By integrating the $\mathrm{C} / \mathrm{T}$ data for $\mathrm{H}=0 \mathrm{~T}$ and $5 \mathrm{~T}$, the entropy at these two fields, $\mathrm{S}(0 \mathrm{~T})$ and $\mathrm{S}(5 \mathrm{~T})$, were calculated 


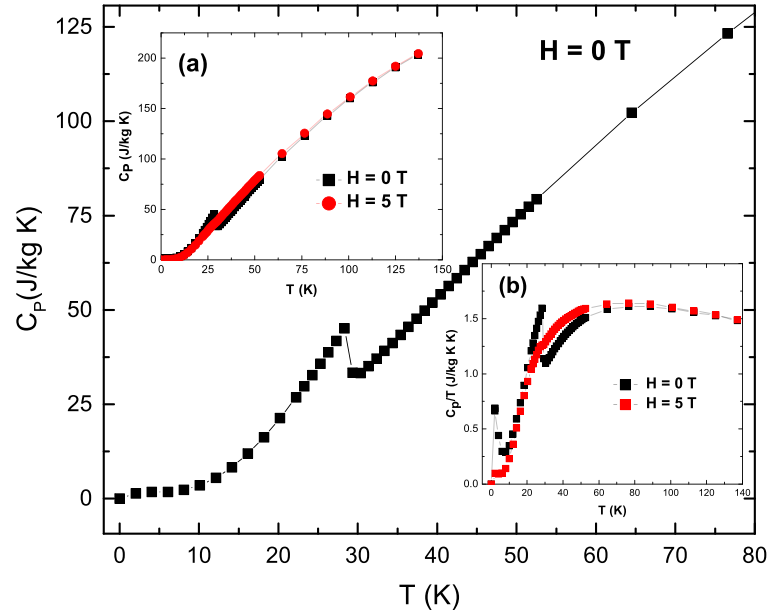

FIG. 8. Temperature (T) dependence of the heat capacity $\left(\mathrm{C}_{\mathrm{p}}\right)$ of $\mathrm{DyRu}_{2} \mathrm{Si}_{2}$ measured at atmospheric pressure and zero applied magnetic field. (a) Heat capacity $\left(\mathrm{C}_{\mathrm{p}}\right)$ measured at $\mathrm{H}=0 \mathrm{~T}$ and $5 \mathrm{~T}$ magnetic field. (b) $\mathrm{C}_{\mathrm{p}} / \mathrm{T}$ vs. $\mathrm{T}$ at $\mathrm{H}=0 \mathrm{~T}$ and $5 \mathrm{~T}$ magnetic field.

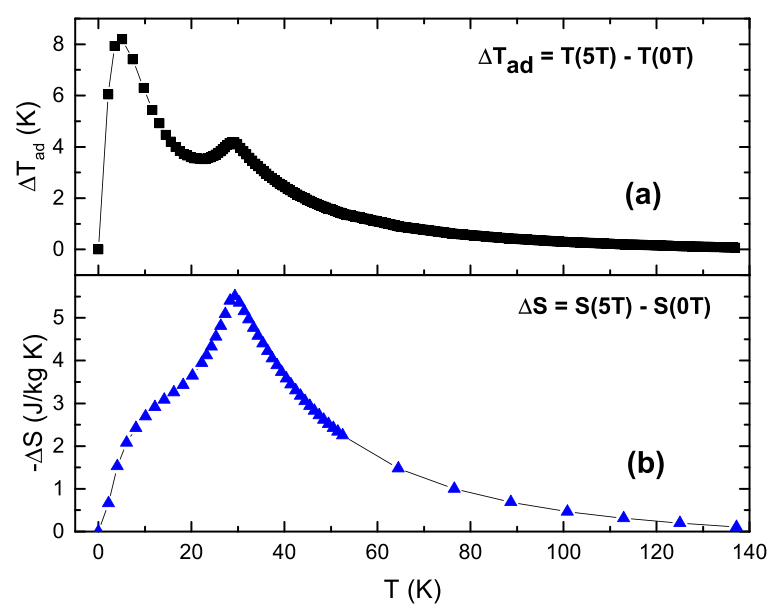

FIG. 9. (a) Temperature (T) dependence of the adiabatic temperature change $\left(\Delta \mathrm{T}_{\mathrm{ad}}\right)$ of $\mathrm{DyRu}_{2} \mathrm{Si}_{2}$. (b) Temperature (T) dependence of the total entropy change $(\Delta \mathrm{S})$ calculated from the heat capacity data.

and subtracted to get $\Delta \mathrm{S}=\mathrm{S}(5 \mathrm{~T})-\mathrm{S}(0 \mathrm{~T})$, as shown in Fig. 9(b). A peak value of $-5.5 \mathrm{~J} / \mathrm{kg} \mathrm{K}$ was found at $\mathrm{T}=29.3 \mathrm{~K}$ which is the Néel temperature, while a value of $-4.6 \mathrm{~J} / \mathrm{kg} \mathrm{K}$ was found from the atmospheric pressure magnetization data for an applied field of $5 \mathrm{~T}$. These numbers are in reasonable agreement. To calculate the adiabatic temperature change $\left(\Delta \mathrm{T}_{\mathrm{ad}}\right), \mathrm{S}(0 \mathrm{~T})$, and $\mathrm{S}(5 \mathrm{~T})$ were first interpolated from the $\mathrm{S}$ vs. $\mathrm{T}$ plots. T vs. S plots were then plotted with the interpolated $\mathrm{S}$ data for 0 and $5 \mathrm{~T}$ magnetic fields and, after interpolating $\mathrm{T}(0 \mathrm{~T})$ and $\mathrm{T}(5 \mathrm{~T}), \Delta \mathrm{T}_{\mathrm{ad}}$ was calculated using the relation $\Delta T_{a d}=T(5 \mathrm{~T})-\mathrm{T}(0 \mathrm{~T})$. Fig. 9(a) shows the adiabatic temperature change $\Delta \mathrm{T}_{\mathrm{ad}}$, and a peak value of $8.2 \mathrm{~K}$ was observed at $\mathrm{T}=5.1 \mathrm{~K}$, which is near the transition temperature $\mathrm{T}_{\mathrm{t}}$. A second peak of magnitude $4.2 \mathrm{~K}$ was observed at $\mathrm{T}=29.2 \mathrm{~K}\left(\mathrm{~T}_{\mathrm{N}}\right)$.

\section{CONCLUSIONS}

Pressure-dependent magnetization measurements have been carried out on $\mathrm{DyRu}_{2} \mathrm{Si}_{2}$, from which we have estimated the volume magnetostriction and entropy changes $\left(\Delta \mathrm{S}_{\mathrm{T}}\right)$ as a function of hydrostatic pressure. We observed the multi-step metamagnetic transitions in the $\mathrm{M}(\mathrm{H})$ curves at atmospheric pressure, the features of which diminished at intermediate pressures $(\mathrm{P}=0.588 \mathrm{GPa}$ and $0.654 \mathrm{GPa})$ and reappeared at higher pressures $(\mathrm{P} \approx 1 \mathrm{GPa})$. Moreover, the saturation magnetization decreased at intermediate pressures, following a near-linear dependence on increasing field, indicating a weaker magnetic ordering. At higher pressures, the saturation magnetization increased again and the $\mathrm{M}(\mathrm{H})$ curves resembled those measured at atmospheric pressure. This trend of pressure dependence was also observed in the $\left(\Delta \mathrm{S}_{\mathrm{T}}\right)$ vs. T curves measured at various pressures. At intermediate pressures, the entropy changes $\left(\Delta \mathrm{S}_{\mathrm{T}}\right)$ decreased, whereas these values gradually increased with higher applied pressures. The variation of the magnetic properties with pressure is likely connected to the modulation of the exchange integral (RKKY-type behavior), caused by a change in interatomic distances due to applied hydrostatic pressure.

\section{ACKNOWLEDGMENTS}

Work at Louisiana State University (S.S.) was supported by the U.S. Department of Energy (DOE), Office of Science, Basic Energy Sciences (BES) under Award No. DE-FG0213ER46946, and heat capacity measurements were carried out at LSU by P.W.A., who is supported by DOE, Office of Science, BES under Award No. DE-FG02-07ER46420. D.P.Y. fabricated the samples and acknowledges the support from the NSF through DMR Grant No. 1306392. Work at Southern Illinois University was supported by DOE, Office of Science, BES under Award No. DE-FG02-06ER46291.

${ }^{1}$ K. A. Gschneidner, Jr., V. K. Pecharsky, and A. O. Tsokol, Rep. Prog. Phys. 68, 1479 (2005).

${ }^{2}$ A. M. Tishin and Y. I. Spichkin, The Magnetocaloric Effect and Its Applications (Institute of Physics, London, 2003).

${ }^{3}$ V. K. Pecharsky and K. A. Gschneidner, Jr., Phys. Rev. Lett. 78, 4494 (1997).

${ }^{4}$ H. Wada and Y. Tanabe, Appl. Phys. Lett. 79, 3302 (2001).

${ }^{5}$ S. Gama, A. A. Coelho, A. de Campos, A. M. G. Carvalho, F. C. G. Gandra, P. J. von Ranke, and N. A. de Oliveira, Phys. Rev. Lett. 93, 237202 (2004).

${ }^{6}$ A. Fujita, S. Fujieda, Y. Hasegawa, and K. Fukamichi, Phys. Rev. B 67, 104416 (2003).

${ }^{7}$ T. Samanta, I. Dubenko, A. Quetz, S. Stadler, and N. Ali, Appl. Phys. Lett. 101, 242405 (2012)

${ }^{8}$ N. T. Trung, L. Zhang, L. Caron, K. H. J. Buschow, and E. Brück, Appl. Phys. Lett. 96, 172504 (2010).

${ }^{9}$ T. Samanta, I. Dubenko, A. Quetz, S. Temple, S. Stadler, and N. Ali, Appl. Phys. Lett. 100, 052404 (2012).

${ }^{10}$ E. Liu, W. Wang, L. Feng, W. Zhu, G. Li, J. Chen, H. Zhang, G. Wu, C. Jiang, H. Xu, and F. de Boer, Nat. Commun. 3, 873 (2012).

${ }^{11}$ S. Stadler, M. Khan, J. Mitchell, N. Ali, A. M. Gomes, I. Dubenko, A. Y. Takeuchi, and A. P. Guimares, Appl. Phys. Lett. 88, 192511 (2006).

${ }^{12}$ J. Liu, T. Gottschall, K. P. Skokov, J. D. Moore, and O. Gutfleisch, Nat. Mater. 11, 620 (2012).

${ }^{13}$ T. Samanta, I. Das, and S. Banarjee, Appl. Phys. Lett. 91, 152506 (2007).

${ }^{14}$ T. Paramanik, K. Das, T. Samanta, and I. Das, J. Appl. Phys. 115, 083914 (2014).

${ }^{15}$ H. Zhang, B. G. Shen, Z. Y. Xu, J. Shen, F. X. Hu, J. R. Sun, and Y. Long, Appl. Phys. Lett. 102, 092401 (2013).

${ }^{16}$ Andrzej Szytuła and Janusz Leciejewicz, Handbook on the Physics and Chemistry of Rare Earths (Elsevier Science Publishers B.V., 1989), Chap. 83, pp. 133-211.

${ }^{17}$ S. Kawano, M. Takahashi, T. Shigeoka, N. Iwata, and T. Kosugi, Appl. Phys. A 74, S646 (2002).

${ }^{18}$ S. Kawano, M. Takahashi, T. Shigeoka, N. Iwata, and M. Bull, Physica B 346-347, 99 (2004). 
${ }^{19}$ B. Andreani, G. L. F. Fraga, A. Garnier, D. Gignoux, D. Maurin, D. Schmitt, and T. Shigeoka, J. Phys.: Condens. Matter 7, 1889 (1995).

${ }^{20}$ N. Iwata, K. Hattori, M. Kadota, M. Takahashi, S. Kawano, and T. Shigeoka, J. Magn. Magn. Mater. 256, 189 (2003).

${ }^{21}$ L. Li, G. Hu, I. Umehara, D. Huo, W. D. Hutchison, T. Namiki, and K Nishimura, J. Alloys Compd. 575, 1 (2013).

${ }^{22}$ K. Hiebl, C. Horvath, P. Rogl, and M. Sienko, J. Magn. Magn. Mater. 37, 287 (1983).

${ }^{23}$ B. Banerjee, Phys. Lett. 12, 16 (1964).

${ }^{24}$ S. Pramanick, P. Dutta, S. Chatterjee, S. Giri, and S. Majumdar, J. Magn. Magn. Mater. 405, 270 (2016).

${ }^{25}$ B. Maji, M. K. Ray, K. G. Suresh, and S. Banerjee, J. Appl. Phys. 116, 213913 (2014).

${ }^{26}$ W. Dunhui, T. Shaolong, H. Songling, Z. Jianrong, and D. Youwei, J. Magn. Magn. Mater. 268, 70 (2004).

${ }^{27}$ X. Chen, Y. Zhuang, J. Yan, and F. Fei, J. Alloys Compd. 479, 35 (2009).

${ }^{28}$ N. T. Trung, Z. Q. Ou, T. J. Gortenmulder, O. Tegus, K. H. J. Buschow, and E. Brück, Appl. Phys. Lett. 94, 102513 (2009).

${ }^{29}$ V. Franco and A. Conde, Int. J. Refrig. 33, 465 (2010).

${ }^{30}$ C. M. Bonilla, J. Herrero-Albillos, F. Bartolomé, L. M. García, M. ParraBorderías, and V. Franco, Phys. Rev. B 81, 224424 (2010).

${ }^{31}$ A. Smith, K. K. Nielsen, and C. R. H. Bahl, Phys. Rev. B 90, 104422 (2014).
${ }^{32}$ M. Doerr, M. Rotter, and A. Lindbaum, Adv. Phys. 54, 1 (2005).

${ }^{33}$ S. Nikitin, A. Tishin, and P. Leontiev, J. Magn. Magn. Mater. 92, 405 (1991).

${ }^{34}$ S. Nikitin, A. Tishin, M. Kuz'min, and Y. Spichkin, Phys. Lett. A 153, 155 (1991).

${ }^{35}$ S. Nikitin, D. Kim, and O. Chistyakov, Zh. Eksp. Teor. Fiz. 71, 1610 (1976).

${ }^{36}$ S. A. Nikitin, Moscow Univ. Phys. Bull. 66, 519 (2011).

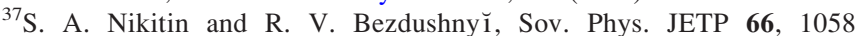
(1987).

${ }^{38}$ K. Tomala, J. P. Sanchez, and R. Kmieć, J. Phys.: Condens. Matter 1, 4415 (1989).

${ }^{39}$ J. K. A. Gschneidner, Y. Mudryk, and V. Pecharsky, Scr. Mater. 67, 572 (2012).

${ }^{40}$ V. Pecharsky, A. Holm, J. K. A. Gschneidner, and R. Rink, Phys. Rev. Lett. 91, 197204 (2003).

${ }^{41}$ T. Samanta, D. L. Lepkowski, A. U. Saleheen, A. Shankar, J. Prestigiacomo, I. Dubenko, A. Quetz, I. W. H. Oswald, G. T. McCandless, J. Y. Chan, P. W. Adams, D. P. Young, N. Ali, and S. Stadler, Phys. Rev. B 91, 020401(R) (2015).

${ }^{42}$ J. L. Wang, L. Caron, S. J. Campbell, S. J. Kennedy, M. Hofmann, Z. X. Cheng, M. F. Md Din, A. J. Studer, E. Brück, and S. X. Dou, Phys. Rev. Lett. 110, 217211 (2013). 